\section{TENDENCIAS RECIENTES DEL CRECIMIENTO METROPOLITANO EN SANTIAGO DE CHILE. ¿HACIA UNA NUEVA GEOGRAFÍA URBANA?'}

Carlos de Mattos², Luis Fuentes ${ }^{3}$, Felipe Link ${ }^{4}$

\section{Resumen}

Frente a la tendencia hacia lo urbano generalizado que se observa actualmente en la mayor parte del mundo, este trabajo tiene el propósito de analizar si esta tendencia también se ha manifestado en el crecimiento del Sistema Urbano Metropolitano de Santiago (SUMS). Para ello se analizaron las tendencias dominantes observadas en las últimas dos décadas, prestando especial atención a los fenómenos de dispersión urbana y recuperación del crecimiento de algunas comunas del área central de la ciudad de Santiago. Al respecto, la información analizada permite concluir que la tendencia dominante de crecimiento urbano continúa siendo hacia la expansión del área urbana del SUMS, al mismo tiempo que también se puede comprobar la recuperación de algunas de las comunas centrales,

\section{RECENT METROPOLITAN GROWTH TRENDS IN SANTIAGO DE CHILE. TOWARDS A NEW URBAN GEOGRAPHY?'}

\author{
Carlos de Mattos², Luis Fuentes 3 , Felipe Link ${ }^{4}$
}

\section{Abstract}

Given the context of widespread urban development observed in most parts of the world, this paper aims to examine whether this trend has manifested itself in the growth of the Metropolitan Urban System of Santiago (SUMS). The authors analyzed the main trends observed over the last two decades, with particular attention to urban sprawl and the recovery of growth in the central area of Santiago. The information analyzed leads to the conclusion that the dominant trend of urban growth is still the expansion of the SUMS; it is also concluded that there is a recovery of some of the central municipalities. These are complex phenomena in which territorial dispersion and 
en un fenómeno complejo en el que dispersión territorial y re-centralización, aparecen como fenómenos complementarios y caracterizados por un patrón de urbanización desigual.

\section{PALABRAS CLAVE: SISTEMA URBANO METROPOLITANO DE SANTIAGO, COMPACTACIÓN Y EXPANSIÓN}

Fecha de recepción: 28.06.13

Fecha de aceptación: 27.01.14

1 Proyecto Fondecyt n. ${ }^{\circ} 1110387$ “Santiago de Chile: de la ciudad de negocios al negocio de las ciudades. Dinámica inmobiliaria y transformación del área metropolitana de Santiago (1975-2010)" y CEDEUS, CONICYT/FONDAP n. ${ }^{\circ} 15110020$.

2 Chile. Arquitecto, profesor Instituto de Estudios Urbanos y Territoriales, Pontificia Universidad Católica de Chile. Investigador Centro de Desarrollo Urbano Sustentable. Correo electrónico: cdmattos@uc.cl

3 Chile. Geógrafo, Magíster en Desarrollo Urbano. Doctor en Arquitectura y Estudios Urbanos. Profesor Instituto de Estudios Urbanos y Territoriales, Pontificia Universidad Católica de Chile. Investigador, Centro de Desarrollo Urbano Sustentable. Correo electrónico: Ifuentes@uc.cl

4 Chile. Sociólogo, Magíster en Investigación Social y Desarrollo, Doctor en Arquitectura y Estudios Urbanos. Profesor Instituto de Estudios Urbanos y Territoriales, Pontificia Universidad Católica de Chile. Investigador, Centro de Desarrollo Urbano Sustentable.Correo electrónico: felipe.link@uc.cl re-centralization are complementary to each other and characterized by unequal urban development patterns.

\section{KEY WORDS: SANTIAGO METROPOLITAN URBAN SYSTEM, URBAN SPRAWL, UNEQUAL URBAN DEVELOPMENT}

\section{Accepted: 27.01.14}

1 Fondecyt Project 1110387 “Santiago de Chile: From the City of Business to the City Business. Real Estate Dynamics and Transformation of the Metropolitan Area of Santiago (1975-2010)" and CEDEUS,CONICYT/FONDAP N 15110020

2 Chile. Architect. Professor, Institute of Urban and Territorial Studies, Pontifical Catholic University of Chile. Researcher, Center for Sustainable Urban Development. Email: cdmattos@uc.cl

3 Chile. Geographer, MSc in Urban Development. PhD in Architecture and Urban Studies. Professor, Institute of Urban and Territorial Studies, Pontifical Catholic University of Chile. Researcher, Center for Sustainable Urban Development. Email: Ifuentes@uc.cl

4 Chile. Sociologist, MA in Social Research and Development, PhD in Architecture and Urban Studies. Professor, Institute of Urban and Territorial Studies, Pontifical Catholic University of Chile. Researcher, Center for Sustainable Urban Development. Email: felipe.link@uc.cl 


\section{Introducción}

Este documento tiene como propósito, analizar las principales tendencias que caracterizan al proceso de transformación de Santiago en los períodos intercensales (1992-2002 y 2002-2011). En este sentido, en los últimos años se ha observado la coexistencia de avances hacia la compactación y dispersión, las cuales no pueden considerarse como tendencias excluyentes, dado que se manifiestan en el contexto de un patrón de desarrollo urbano mucho más complejo que el que se había impuesto en el pasado. En otras palabras, en lo que sigue se busca demostrar que compactación, dispersión y otras tendencias pueden coexistir en tanto procesos complementarios, en el contexto de la nueva dinámica urbana que se ha impuesto con el avance de la globalización.

Para realizar este análisis, se utilizó la información sobre el número de viviendas de los censos 1992 , 2002 y del precenso 2011. En este sentido se asume que el número de viviendas, su distribución en la ciudad y su variación cuantitativa durante un

ARTICULO. Tendencias recientes del crecimiento metropolitano en Santiago de Chile. ¿Hacia una nueva geografía urbana? / Carlos de Mattos, Luis Fuentes, Felipe Link período, son indicadores válidos para analizar las tendencias de crecimiento urbano, en la medida en que expresan el dinamismo del sector inmobiliario residencial y reflejan las decisiones de individuos, familias y empresas por localizarse en determinados lugares. Para este trabajo, este indicador se ha utilizado en reemplazo de la cantidad de habitantes, debido a los problemas que fueron detectados por una comisión especial de expertos ${ }^{5}$ en la realización del Censo 2012. En este sentido, se puede mencionar que un cálculo realizado con los números entregados inicialmente sobre población por comuna según el Censo del 2012, ahora sujetas a revisión, mostraban tendencias similares ${ }^{6}$.

Reconociendo los actuales patrones de urbanización y la emergencia de un nuevo campo de externalidades de la ciudad, producto de la influencia de tendencias estructurales y coyunturales, para este análisis se ha considerado al área urbana configurada en torno a esta ciudad como "Sistema Urbano Metropolitano de Santiago" (SUMS). El SUMS está compuesto por 47 comunas de la Región Metropolitana de Santiago (RMS), considerando las 34 del Área Metropolitana de Santiago

5 El Censo de Población y Vivienda del año 2012 presentó problemas en el proceso de validación de datos. Con el objetivo de usar información de mayor confiabilidad, se trabajó con los datos sobre número de viviendas identificadas en el precenso del 2011 los cuales no fueron objetados por la comisión externa revisora que analizó el Censo 2012

6 Mattos y Fuentes, 2013.

revista invi № 81 / Agosto 2014 / Volumen № 29: 193-219 195 
(AMS) que componen el núcleo del sistema (comunas de la Provincia de Santiago más San Bernardo y Puente Alto) y por 13 comunas del entorno regional, que aquí se denominan como periurbano expandido. Estas últimas, cumplían en el 2002 con el requisito de que el 15\% o más de su población económicamente activa que trabajaba en el AMS, conforme al criterio establecido por la Organización para la Cooperación Económica y el Desarrollo - $\mathrm{OECD}^{7}$ - como requisito para considerar a una determinada unidad territorial como parte de un sistema urbano.

Así, con el propósito de establecer un marco general de referencia para el análisis que motiva este artículo, en primer lugar se realiza una presentación sintética sobre las principales transformaciones urbanas que han comenzado a producirse en la mayor parte del mundo bajo el impacto del avance de la globalización y de la informacionalización, considerando en particular, cómo ello se ha manifestado en el caso de las principales aglomeraciones urbanas latino americanas y, en particular, en Santiago. Con este propósito, se realiza una breve presentación y discusión de los principales cambios estructurales producidos desde las últimas décadas del siglo pasado y se analizan sus impactos urbanos y territoriales de mayor relevancia. Posteriormente se presenta un análisis por comunas en función de las principales tendencias de crecimiento del parque habitacional identificadas entre 1992 y 2011 para la principal aglomeración urbana de Chile.

Luego, con el objetivo de analizar los patrones y las dinámicas de crecimiento urbano del SUMS, se realizan dos tipos complementarios de análisis, en base a sendas formas de dividir la ciudad por zonas. El primer análisis por zona se realizó en función de la agrupación de las comunas respecto al anillo vial, Américo Vespucio y en relación a la continuidad de la mancha urbana. En función de estos dos criterios, el SUMS se dividió en tres zonas: (a) comunas que se encuentran localizadas mayoritariamente al interior del anillo vial; (b) comunas que se encuentran fuera de dicho anillo; y, (c) comunas del entorno regional separadas físicamente de la mancha urbana contigua. En el segundo análisis por zonas, se tomó como referencia la estructura urbana de la ciudad y se modificó y adaptó el clásico patrón de anillos concéntricos desde el interior hacia el entorno regional. De esta manera, se dividió al SUMS en cuatro áreas según

$7 \quad 0 E C D, 2012$. 
la localización de las comunas: (a) centro histórico, que corresponde a la Comuna de Santiago; (b) primera corona que contiene a aquellas comunas que rodean al centro histórico y que colindan con las comunas del borde de la mancha urbana; (c) corona exterior que comprende a las comunas que se encuentran localizadas en el borde de la mancha urbana contigua o del AMS; y, (d) periurbano expandido que corresponde a las comunas del entorno regional del AMS que cumplen con el requisito expuesto por la OECD para establecer la vinculación de un área a un sistema urbano.

Por último, con el objetivo de caracterizar la estructura y composición social del SUMS en sus diferentes zonas e identificar un eventual patrón socio-demográfico que ayude a interpretar las formas del crecimiento metropolitano, se analizan algunos datos de la Encuesta de Caracterización Socio-Económica Nacional (CASEN) de 2011. Específicamente, se analizan datos de estructura familiar, tipo y tenencia de vivienda, migración metropolitana y categoría socio-ocupacional, entendidas

8 Centro histórico (Santiago), primera corona (Cerrillos, Cerro Navia, Conchalí, El Bosque, Estación Central, Independencia, La Cisterna, La Granja, La Pintana, Lo Espejo, Lo Prado, Macul, Ñuñoa, Pedro Aguirre Cerda, Providencia, Quinta Normal, Recoleta, Renca, San Joaquín, San Miguel, San Ramón y Vitacura), corona exterior (Huechuraba, Las Condes, La Florida, La Reina, Lo Barnechea, Maipú, Peñalolén, Pudahuel, Puente Alto, Quilicura y San Bernardo), periurbano expandido (Buin, Calera de Tango, Colina, Curacaví, El Monte, Isla de Maipo, Lampa, Padre Hurtado, Paine, Peñaflor, Pirque, San José de Maipo y Talagante) otras comunas (Melipilla, San Pedro, Alhue, María Pinto y Til-Til). como variables que dan sentido a los procesos de expansión y verticalización en las diferentes comunas del sistema. De esta manera, la caracterización de nuevas geografías socio-espaciales en el SUMS contribuye a aportar elementos de juicio para la discusión sobre los impactos socio-territoriales de las tendencias emergentes de la urbanización en Santiago y para apoyar la hipótesis de un patrón de urbanización desigual. En el apartado final, se presentan las principales conclusiones del trabajo.

\section{Hacia una nueva ronda de metamorfosis urbana}

Entre los impactos producidos con el avance de la nueva fase de modernización capitalista iniciada durante las últimas décadas del siglo pasado, en un número creciente de países en el mundo, se destaca el desencadenamiento de un proceso de transformación urbana que, por su alcance y profundidad, ha sido caracterizado como "una nueva 
ronda de metamorfosis urbana". Con la evolución de esta metamorfosis, cobró fuerza la transición desde la forma urbana "ciudad" hacia otra que se manifiesta como lo urbano generalizado, tal como había sido anticipado por Lefebvre ${ }^{10}$ varias décadas atrás.

La mayor parte de los estudios dedicados al análisis de esta metamorfosis coinciden en que -más allá de la incidencia de un conjunto de factores políticos, económicos, sociales, etc., inherentes a la específica dependencia de trayectoria condicionada por la evolución histórica de cada lugar-, en lo urbano emergente, incidieron básicamente dos fuerzas constitutivas de esta fase de modernización capitalista globalizada:

a) En primer término, la dinámica económica que se desencadenó con la adopción y aplicación de las prescripciones del discurso teórico ideológico neoliberal, que impuso un enfoque de gestión pública basado en los principios de subsidiaridad estatal y de asociación públicoprivada, el cual ha sido caracterizado genéricamente como gobernanza "empresarialista" ${ }^{11}$;

b) Y, en segundo término, la que resulta de la compresión tiempo-espacio ${ }^{12}$ producida bajo el efecto de la incontrolable intensificación de

9 Soja, 1989, p. 173.

10 Lefebvre, 1970.

11 Harvey, 1989.

12 Harvey, 1990.

198 revista invi № 81 / Agosto 2014 / Volumen No 29: 193-219 la conectividad y de la movilidad provocada por la difusión y adopción de las nuevas tecnologías de la información y la comunicación (NTICs), junto al explosivo aumento de la utilización de los medios motorizados de transporte y, en particular, del automóvil.

En lo fundamental, importa tener en cuenta que bajo el impulso inter-relacionado de la restructuración neoliberal y de la revolución informacional se afirmaron condiciones propicias para que se produjese un progresiva ampliación y reticulación del campo territorial de externalidades en la dirección señalada por Dematteis: "[...] los nuevos campos de externalidad no tienen ya una forma de área compacta ni un radio tan limitado, sino que se configuran como retículas articuladas en centros y sistemas urbanos pequeños o grandes, en extensiones territoriales macro regionales"13. ${ }^{\prime \prime}$. crucial importancia de este cambio, radica en que al generar condiciones favorables para un continuo aumento/diversificación de las opciones territoriales para la localización de las familias y las empresas en un ámbito cada vez más extenso, dicha ampliación del campo de externalidades contribuyó a impulsar una incontrolable dispersión territorial de las áreas urbanas.

13 Dematteis, 1998, p. 25. 
Lo urbano que emergió bajo el efecto de estas fuerzas, ha llevado a la configuración de una nueva forma urbana que presenta diferencias sustantivas con la dominante en la fase industrial-desarrollista: es "una nueva forma porque incluye en la misma unidad espacial urbanizada, áreas urbanizadas y tierra agrícola, espacio abierto y áreas residenciales de alta densidad: hay múltiples ciudades en un paisaje discontinuo. Es una metrópolis multicentrada que no corresponde a la separación tradicional entre ciudad central y sus suburbios. Contiene núcleos de diferentes tamaños e importancia funcional distribuidos a lo largo de una amplia extensión territorial siguiendo las líneas de transporte"14. La presencia de esta forma ha dado lugar a la aparición de expresiones tales como ciudad difusa, ciudad desbordada, ciudad de ciudades, postmetrópolis, ciudad región, región urbana, ciudad de baja densidad, archipiélago metropolitano, etc., etc., con las que se ha buscado aludir a diversos rasgos que marcan sus principales diferencias con la forma urbana que había caracterizado a la ciudad industrial.

Desde el momento en que este cambio se puede observar en distintas partes del mundo, se ha planteado la discusión acerca de si sigue siendo pertinente calificar a esta nueva forma urbana como "ciudad" o si se debe reconocer que ella

14 Castells, 2010, p. 273. conforma un fenómeno diferente. Más allá de las diversas posturas asumidas a este respecto, lo que parece haber quedado fuera de toda discusión es que "dentro de este campo de desarrollo urbano, extendido y cada vez más universal, las aglomeraciones se forman, expanden, contraen y transforman de manera continua, pero siempre a través de densas redes de relaciones con otros lugares, territorios y escalas, incluidos los ámbitos tradicionalmente clasificados como ajenos a la condición urbana"15.

De hecho, diversas investigaciones han comprobado que estas tendencias ya están presentes en las principales aglomeraciones urbanas latinoamericanas desde las últimas décadas del siglo pasado, lo cual ha sido explícitamente reconocido por el balance sobre la situación actual de las mismas realizado por ONU-HABITAT: "la expansión urbana ha hecho que grandes ciudades desborden los límites administrativos de sus municipios y terminen absorbiendo físicamente otros núcleos urbanos mediante un proceso de conurbación. El resultado ha sido la aparición de áreas urbanas de grandes dimensiones territoriales, a veces formalizadas en un área metropolitana, integradas por múltiples municipios y con intensa actividad económica. [...]"16.

15 Brenner, 2013, p. 61.

16 ONU-HABITAT, 2012, p. 33, 34. 
Ha sido justamente la generalización de esta metamorfosis urbana a escala planetaria lo que ha obligado a replantear los criterios para poder realizar la identificación y medición de la nueva configuración urbana. A este respecto, se han realizado diversas propuestas por parte de organismos especializados nacionales e internacionales, entre los que cabe destacar algunos trabajos recientes de la Unión Europea ${ }^{17}$ y de la OECD ${ }^{18}$, que han considerado nuevos criterios y metodologías para hacer frente a este complejo problema de identificación urbana, que todavía está lejos de llegar a un solución de consenso.

¿Cuáles son las principales tendencias observadas en la evolución urbana en América Latina según la evidencia empírica reciente? En lo esencial, los resultados de los últimos censos de población difundidos hasta ahora para diversos países latinoamericanos, han confirmado la persistencia de la tendencia a la expansión/dispersión del crecimiento metropolitano. En este sentido, se pueden mencionar algunas conclusiones de las evaluaciones realizadas con posterioridad a la difusión de dichos resultados, en las que se destacan algunas peculiaridades de la tendencia dominante hacia lo urbano generalizado.

17 Damon, 2012

18 OECD, 2012.

200 revista invi № 81 / Agosto 2014 / Volumen № 29: 193-219
Así, por ejemplo, en un estudio sobre la evolución de las principales áreas urbanas de Brasil, realizado para el Observatorio das Metropoles de la Universidad Federal de Rio de Janeiro ${ }^{19}$, se concluye que los datos del Censo 2010 indican que hay una difusión del fenómeno de la metropolización, en procesos en los que las periferias metropolitanas presentan ritmos de crecimiento mayores y emigración bastante considerable venida del núcleo. Al mismo tiempo también se comprueba que "esos núcleos presentan un incremento poblacional aún muy importante, además de concentrar también buena parte de los empleos y de las empresas que comandan la economía, lo que pone en evidencia, en primer lugar, que aún subsiste una relativa presión poblacional sobre las áreas centrales que ocurre simultáneamente con una dispersión poblacional hacia las periferias, con tendencia a la formación de tejidos urbanos cada vez más expandidos $y$, en segundo, que los núcleos mantienen la tendencia a la concentración del poder económico"20.

En una dirección análoga, en un informe de la Red de Observatorios de la Comunidad Europea ${ }^{21}$, para el Distrito Federal (DF) y la Zona Metropolitana del Valle de México (ZMVM), se concluye que las cifras preliminares del Censo 2010 indican que "[...] aunque el componente DF de la ZMVM tiene

\footnotetext{
19 Observatório das Metrópoles, 2011.

20 Ribeiro, Rodrigues y Silva, 2011, p. 203.

21 Red de Observatorio de la Comunidad Europea, 2011, p. 14.
}

ARTÍCULO: Tendencias recientes del crecimiento metropolitano en Santiago de Chile. ¿Hacia una nueva geografía urbana? / Carlos de Mattos, Luis Fuentes, Felipe Link 
tasas de crecimiento social negativas, estas se compensan en parte debido a que muchos de los que salen del DF [...] en realidad emigran a los municipios conurbados del Estado de México y, a su vez, siguen llegando tanto de esta entidad como de otras entidades del país, flujos importantes de inmigrantes al DF". A esto se agrega "[...] que las migraciones del DF hacia los municipios conurbados del Estado de México forman parte de un proceso de desconcentración de población, del centro a la periferia, en la ZMVM, motivado principalmente por el elevado costo del suelo en las delegaciones centrales $[\ldots .$.$] ".$

Finalmente, un análisis de los datos preliminares del Censo del 2010 de Argentina, concluye que: "el crecimiento de la Región Metropolitana de Buenos Aires (RMBA) se debe a las altas tasas de los partidos de la periferia (segundo cordón) que más que duplican y hasta cuadruplican la tasa total de la Región y compensan la pérdida de población de la Ciudad Autónoma de Buenos Aires (CABA) y de los partidos más cercanos (primer cordón). "[...] La Región Metropolitana con un nivel de crecimiento que acompaña al del país, lo hace por su periferia y con ritmos muy diferentes a los del núcleo originario en el que se observa pérdida de población"22 .

Frente al hecho de que en algunos casos se ha comprobado que esta tendencia evolucionó asociada a

22 Alonso, 2011, p. 72. una recuperación del crecimiento demográfico y/o productivo de ciertas áreas centrales, parece importante considerar que esto no representa un proceso de crecimiento alternativo, sino complementario en una dinámica de urbanización generalizada pues, como sostiene Brenner 23 "la urbanización comprende la concentración y la extensión: estos momentos están dialécticamente interrelacionados, en la medida en que se presuponen y contrarrestan mutuamente de forma simultánea". Por lo tanto, interpretar la recuperación del crecimiento de las áreas centrales como una disyuntiva entre compactación y dispersión, implica dejar fuera del análisis la incidencia de los factores estructurales que explican la actual metamorfosis urbana, lo que invalida las conclusiones que se puedan extraer del mismo.

En este sentido, es importante destacar que para el caso de Santiago, esta tendencia ya había sido claramente prevista y explicada en un amplio estudio publicado en diciembre de 1971 por el Centro Interdisciplinario de Desarrollo Urbano y Regional (CIDU) de la Pontificia Universidad Católica de Chile, sobre las perspectivas de desarrollo de la Región Central de Chile ${ }^{24}$. Este estudio, en base a la información entonces disponible, ya identificaba la tendencia hacia la formación de una amplia macrozona central predominantemente urbana, que

23 Brenner, 2013, p. 62.

24 CIDU, 1971 
corresponde a lo que en este artículo se considera como el SUMS. Por otra parte, trabajos realizados posteriormente por Duccir ${ }^{25}$, Mattos ${ }^{26}$, Greene y Solar ${ }^{27}$, Fuentes y Sierralta ${ }^{28}$, Hidalgo, Borsdorf y Sánchez ${ }^{29}$, Escolano y Ortiz ${ }^{30}$, Rodríguez Vignoli ${ }^{31}$, López-Morales, Gasic Klett y Meza Corvalán ${ }^{32}$, entre otros, han aportado elementos de juicio complementarios sobre la coexistencia de tendencias hacia la concentración y hacia la dispersión en la evolución del AMS.

Dado el carácter estructural de los factores que inciden en esta metamorfosis, resulta poco probable que mientras éstos mantengan su vigencia, las tendencias constitutivas que la caracterizan puedan revertirse o desaparecer. En otras palabras, el desencadenamiento de la evolución hacia lo urbano generalizado es un hecho asociado en forma indisoluble a una nueva organización y dinámica capitalista re-escalada en un espacio mundial de acumulación y, por lo tanto, su persistencia puede considerarse como inexorable. En este sentido, como se analiza a continuación, el caso de la evolución reciente del Sistema Urbano Metropolitano

25 Ducci, 1998.

26 Mattos, 2004.

27 Greene y Solar, 2004.

28 Fuentes y Sierralta, 2004.

29 Hidalgo, Borsdorf y Sánchez, 2007.

30 Escolano y Ortiz, 2007.

31 Rodríguez Vignoli, 2012

32 López-Morales, Gasic Klett y Meza Corvalán, 2012. de Santiago, constituye un elocuente testimonio a este respecto.

\section{¿Qué pasó en Santiago entre 1992 y 2012? ¿Compactación 0 expansión?}

El precenso realizado en 2011 reportó para el SUMS un crecimiento de más de 435 mil viviendas con respecto al 2002, cifra superior en casi 100 mil viviendas a las contabilizadas para el período intercensal anterior. Esto a pesar de que el censo realizado en 2012 consignó una disminución del ritmo de crecimiento de la población, que pasó de $1,5 \%$ a $1,0 \%$ anual.

Las 10 comunas que concentraron el mayor aumento de viviendas en el periodo 1992-2012 (véase tabla 1) representan aproximadamente $62 \%$ del crecimiento del SUMS. Todas ellas, a excepción de Santiago, Nuñoa y Providencia, se encuentran localizadas en la corona exterior. De los datos 
TABLA 1. RÁNKING DE LAS 10 COMUNAS QUE CONCENTRARON MAYOR CRECIMIENTO DE VIVIENDAS ENTRE 1992 Y 2012

\begin{tabular}{lllllll} 
Comuna & 1992 & 2002 & 2011 & Diferencia 1992-2002 & Diferencia 2002-2011 & Diferencia 1992-2011 \\
\hline Puente Alto & 64.331 & 136.668 & 163.578 & 72.337 & 26.910 & 99.247 \\
\hline Maipú & 65.780 & 126.972 & 151.208 & 61.192 & 24.236 & 85.428 \\
\hline Santiago & 63.730 & 77.514 & 143.649 & 13.784 & 66.135 & 79.919 \\
\hline Las Condes & 55.791 & 82.099 & 103.794 & 26.308 & 21.695 & 48.003 \\
\hline Quilicura & 9.710 & 35.242 & 56.415 & 25.532 & 21.173 & 46.705 \\
\hline Ñuñoa & 47.215 & 54.692 & 76.513 & 7.477 & 21.821 & 29.298 \\
\hline Pudahuel & 34.207 & 48.818 & 63.266 & 14.611 & 14.448 & 29.059 \\
\hline San Bernardo & 42.775 & 63.070 & 70.265 & 20.295 & 7.195 & 27.490 \\
\hline Providencia & 38.214 & 51.183 & 64.073 & 12.969 & 12.890 & 25.859 \\
\hline La Florida & 83.406 & 97.174 & 109.050 & 13.768 & 11.876 & 25.644 \\
\hline Total SUMS & 1.257 .411 & 1.605 .840 & 2.044 .473 & 348.429 & 438.633 & 787.062 \\
\hline
\end{tabular}

Fuente: Elaboración proyecto Fondecyt n. ${ }^{\circ}$ 1110387, en base a información Censos 1992, 2002 y Precenso 2011.

expuestos se destaca la diferencia de las tres primeras comunas respecto al resto, ya que concentran un tercio del crecimiento del SUMS entre 1992 y 2011. En 1992 representaban el 15\% de las viviendas del SUMS y en 2011 pasan a representar el 22\%. El ritmo de crecimiento fue de $76 \%$ en el primer período, el cual decayó a 34\% en el segundo.

Otro aspecto relevante que se puede inferir de esta información es el relativo a la Comuna de Santiago, la cual en el primer período creció sólo en 13 mil viviendas y en el segundo en más de 66 mil, posicionándose como la Comuna con el mayor crecimiento en el período 2002-2011.

Respecto al período 1992-2002, se puede comprobar que el SUMS concentró el 98\% de las viviendas de la RMS. Las comunas que más crecieron fueron Puente Alto, Maipú, Las Condes y Quilicura, las cuales representan más del 50\% del crecimiento del SUMS. Llama la atención sobre todo, el explosivo crecimiento de Quilicura que multiplicó por 3,6 su parque habitacional en diez años; también destaca la magnitud del crecimiento de las dos primeras comunas, las cuales captaron por si solas 
MAPA 1. CRECIMIENTO DE LAS VIVIENDAS DEL SISTEMA URBANO METROPOLITANO DE SANTIAGO ENTRE 2002 Y $2011(\%)$

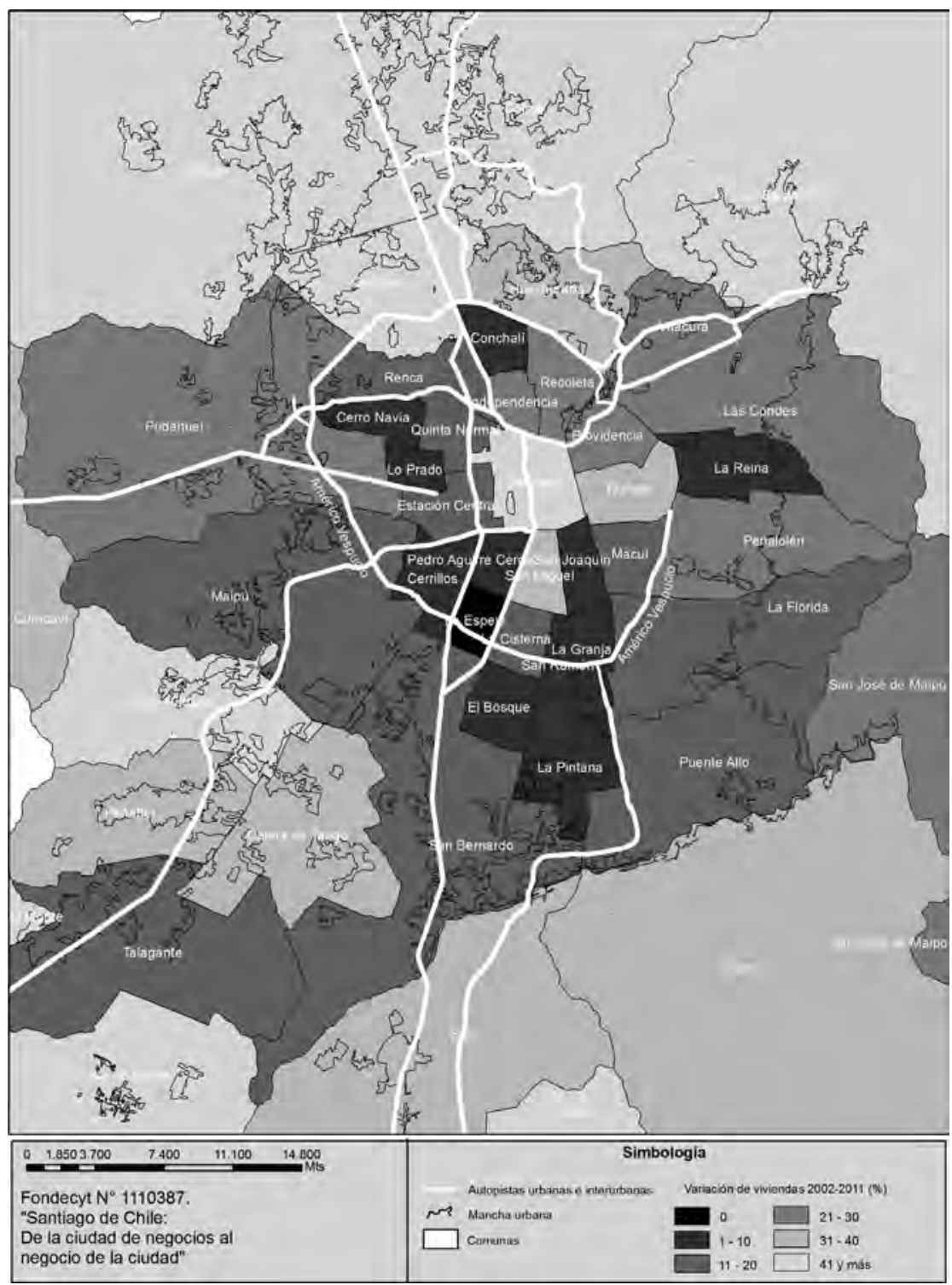


casi el 40\% del crecimiento habitacional del Sistema Urbano. Cabe señalar que todas las comunas se encuentran fuera del anillo vial Américo Vespucio y, a excepción de La Florida, son comunas borde.

Respecto al crecimiento entre 2002 y 2011, Santiago, Puente Alto y Maipú fueron las tres con mayor crecimiento, las cuales en conjunto explican un cuarto del crecimiento del Sistema Urbano. Dentro de las diez comunas que muestran mayor crecimiento de su parque habitacional, ocho de ellas se encuentran fuera del anillo Américo Vespucio, es decir en la corona exterior o en el periurbano expandido del SUMS. Santiago, Providencia y Nuñoa representan los únicos casos con altos niveles de crecimiento de viviendas dentro del anillo vial Américo Vespucio.

En el mapa 1 se observa la espacialización de la variación porcentual de viviendas del SUMS entre 2002 y 2011. En términos generales se observa un mayor crecimiento porcentual de las comunas

ARTíCULO: Tendencias recientes del crecimiento metropolitano en Santiago de Chile. ¿Hacia una nueva geografía urbana? / Carlos de Mattos, Luis Fuentes, Felipe Link

\section{GRÁFICO 1. DISTRIBUCIÓN PORCENTUAL DE LAS VIVIENDAS POR ZONAS DE LA CIUDAD ${ }^{33}(\%)$}

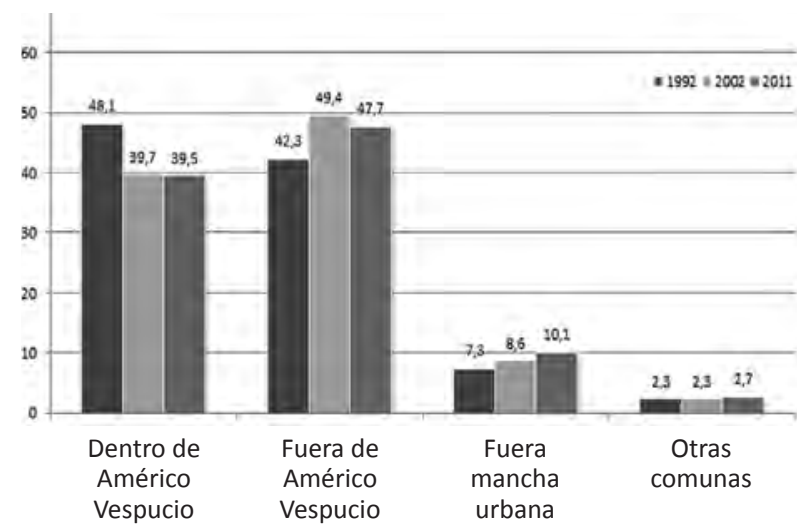

Fuente: Elaboración proyecto Fondecyt n. ${ }^{\circ} 1110387$, en base a información Censos 1992, 2002 y precenso 2011, INE.

periféricas, ya sea en la corona exterior y sobre todo en el periurbano expandido. También se

33 Dentro de Américo Vespucio (Cerrillos, Cerro Navia, Conchalí, Estación Central, Independencia, La Cisterna, La Granja, Lo Espejo, Lo Prado, Macul, Ñuñoa, Pedro Aguirre Cerda, Providencia, Quinta Normal, Recoleta, Renca, San Joaquín, San Miguel, San Ramón y Santiago), fuera de Américo Vespucio (El Bosque, Huechuraba, La Florida, La Pintana, La Reina, Las Condes, Lo Barnechea, Maipú, Peñalolén, Pudahuel, Puente Alto, Quilicura, San Bernardo y Vitacura), fuera de la mancha urbana contigua (Buin, Calera de Tango, Colina, Curacaví, El Monte, Isla de Maipo, Lampa, Padre Hurtado, Paine, Peñaflor, Pirque, San José de Maipo y Talagante), otras comunas (Melipilla, San Pedro, Alhue, María Pinto y Til-Til).

revista invi № 81 / Agosto 2014 / Volumen №29: 193-219 205 
MAPA 2. CLASIFICACIÓN DE LAS COMUNAS DEL SUMS SEGÚN SU LOCALIZACIÓN.

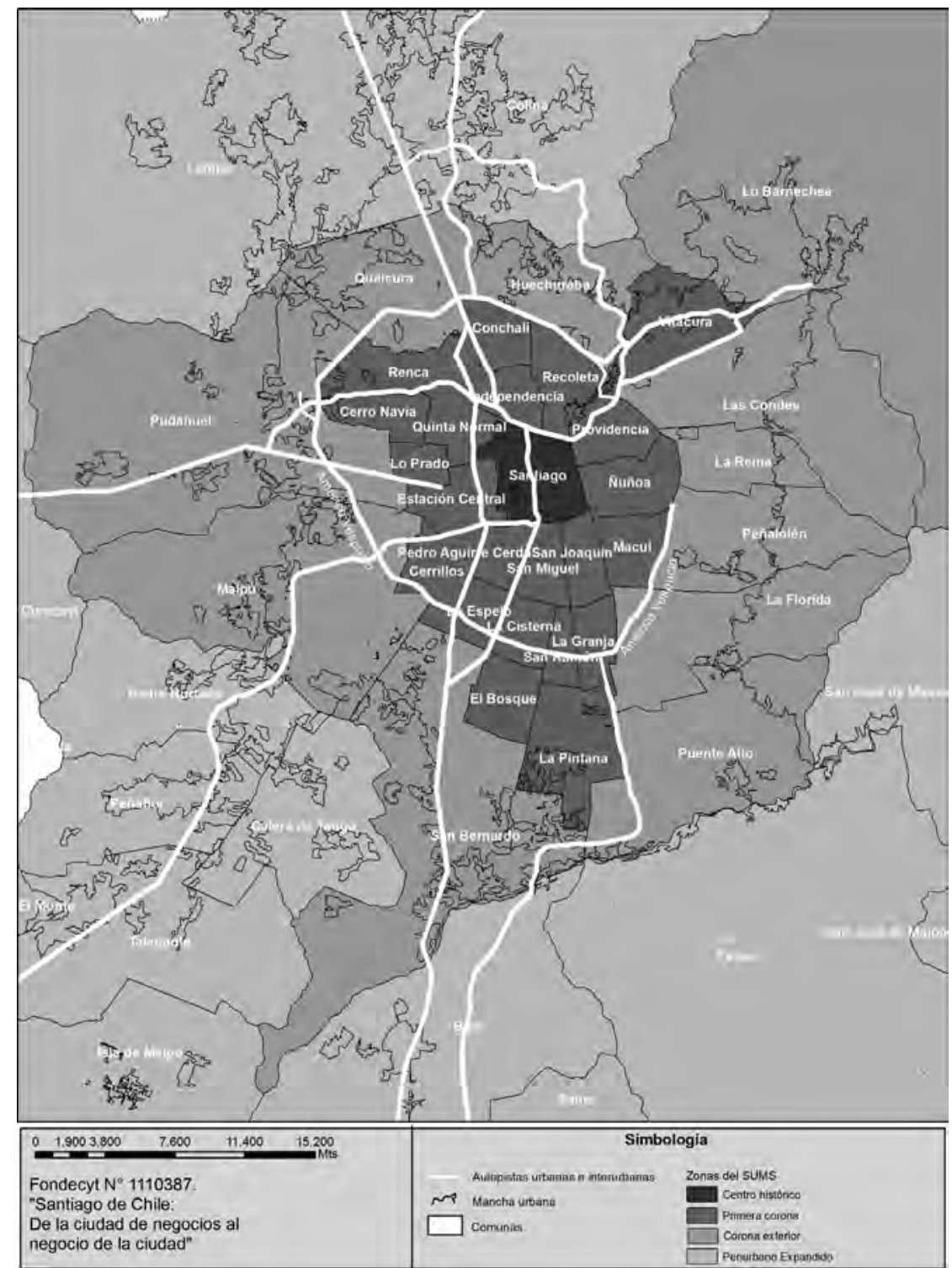


puede comprobar un crecimiento importante en Santiago, Nuñoa y San Miguel. Por otro lado, se comprueba un crecimiento mucho más lento en algunas comunas localizadas preferentemente en la primera corona al sur (San Joaquín, Pedro Aguirre Cerda, Lo Espejo, San Ramón y La Granja), en el poniente (Cerro Navia y Lo Prado) y en el norte (Conchalí). La excepción a esta tendencia la constituye el lento crecimiento de comunas fuera del anillo, como El Bosque, La Pintana y La Reina.

Considerando el mapa y las cifras absolutas, se pueden identificar tres vectores de crecimiento urbano principales. En primer lugar el sector norte (Quilicura, Lampa, y Colina) que suma más de 40 mil viviendas, lo cual representa más del 10\% del crecimiento del parque habitacional entre 2002 y 2011; en segundo lugar, un eje central compuesto por Santiago, Ñuñoa y San Miguel, con más de 95 mil viviendas representando un $22 \%$ del crecimiento del SUMS en igual período y finalmente las comunas más pobladas (Puente Alto y Maipú), que aportan más de 50 mil viviendas, equivalentes al $10 \%$ del crecimiento demográfico. En conjunto estas seis comunas representan el $40 \%$ del crecimiento del SUMS en los últimos diez años, lo cual da cuenta de la heterogeneidad y complejidad del crecimiento urbano en este período. Otro aspecto relevante, es la diversidad de la ubicación territorial de las comunas que más contribuyeron al mismo, ya que estas comunas no sólo se encuentran

\section{GRÁFICO 2. DISTRIBUCIÓN PORCENTUAL DE LAS VIVIENDAS POR ZONAS DEL SISTEMA URBANO METROPOLITANO DE SANTIAGO (\%)}

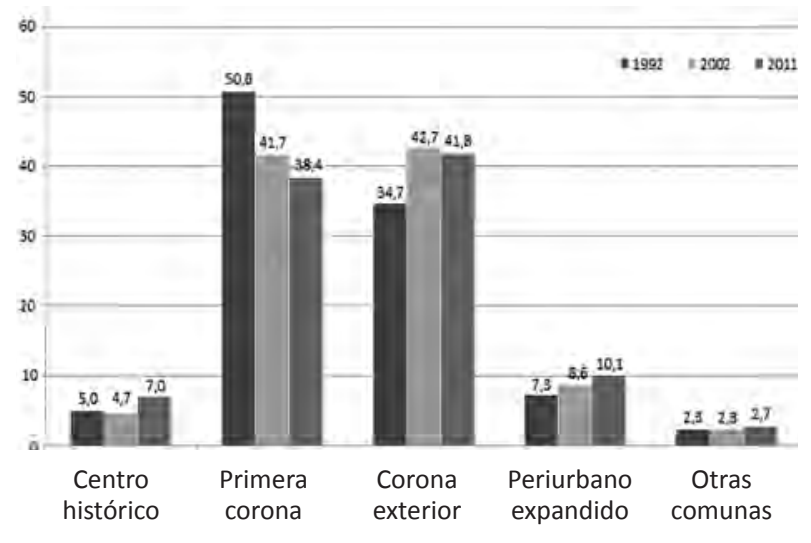

Fuente: Elaboración proyecto Fondecyt n.$^{\circ} 1110387$, en base a información Censos 1992, 2002 y precenso 2011, INE.

ubicadas en distintos sectores del SUMS, definidos por la metodología de este trabajo, sino también en distintos lugares geográficos de la ciudad.

Si se analiza la distribución porcentual de viviendas del SUMS teniendo como referencia el anillo vial Américo Vespucio y los límites de la mancha urbana contigua, es posible comprobar el progresivo vaciamiento del interior del anillo entre 1992 y 2011, el cual disminuye en más de 8 puntos porcentuales, mientras que la localizada fuera del 


\section{GRÁFICO 3. PROPORCIÓN DE LA EDIFICACIÓN AUTORIZADA EN VIVIENDAS POR ZONAS DEL SISTEMA URBANO METROPOLITANO DE SANTIAGO EN PERÍODOS INTERCENSALES}

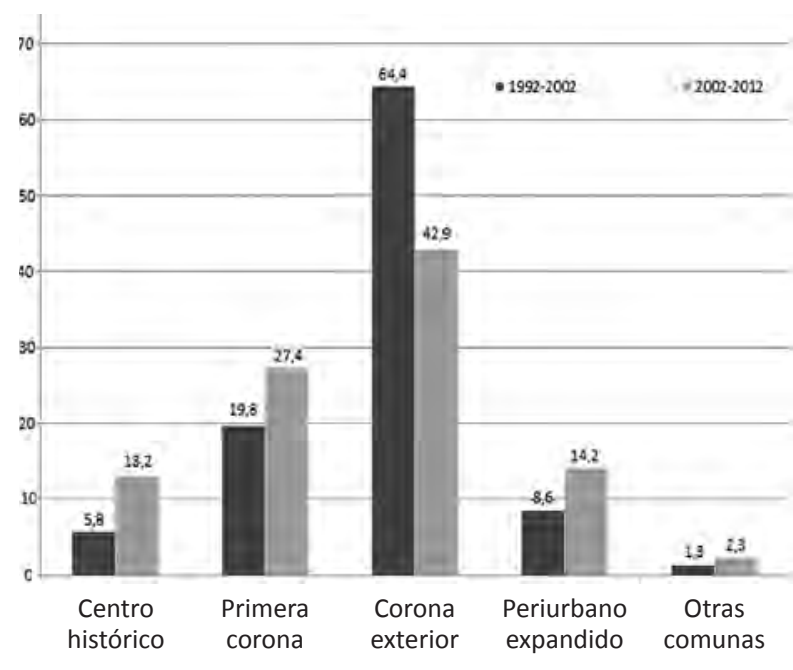

Fuente: Elaboración proyecto Fondecyt n. ${ }^{\circ} 1110387$, en base información del INE

mismo aumenta en más de $5 \%$ y la ubicada fuera de los límites de la mancha contigua consolidada pasa de $7 \%$ a $10 \%$.

Si se analiza el fenómeno por períodos, es posible observar que en el segundo, la distribución de las viviendas prácticamente se mantiene en el caso de las comunas ubicadas dentro del anillo y disminuye levemente en las comunas que se encuentran fuera del anillo. Cabe señalar que las comunas que no integran el SUMS, y que en el gráfico son catalogadas como "otras comunas" (Melipilla, San Pedro, Alhue y Tiltil), también aumentan su participación levemente, aunque su aporte a la región es marginal en términos de su parque habitacional.

Si complejizamos esta clasificación y detallamos un poco más la localización de las comunas (ver mapa 2) diferenciándolas entre centro histórico, que corresponde a la Comuna de Santiago, primera corona que corresponde a aquellas que están al interior de la mancha urbana limitando con las comunas borde de la ciudad, corona exterior que comprende a las comunas borde de la mancha urbana, y comunas del periurbano expandido, que son las que están en el entorno regional, las tendencias de crecimiento urbano pueden caracterizarse en los siguientes párrafos, mapas y gráficos.

El parque habitacional del SUMS pasa a distribuirse en la forma en que se muestra en el gráfico 2, en el que se observa que el centro histórico a pesar del espectacular crecimiento que registró en el último período inter-censal, solamente pudo superar en $2 \%$ la proporción de viviendas que tenía en el año 1992 respecto al resto de los sectores. También se puede observar la diminución constante de viviendas que concentran las comunas de la primera corona, tanto aquellas ubicadas dentro como fuera del anillo Américo Vespucio, las que pierden más 


\section{GRÁFICO 4. DISTRIBUCIÓN DE LOS TAMAÑOS DE HOGAR POR SECTORES DE LA CIUDAD (\%)}

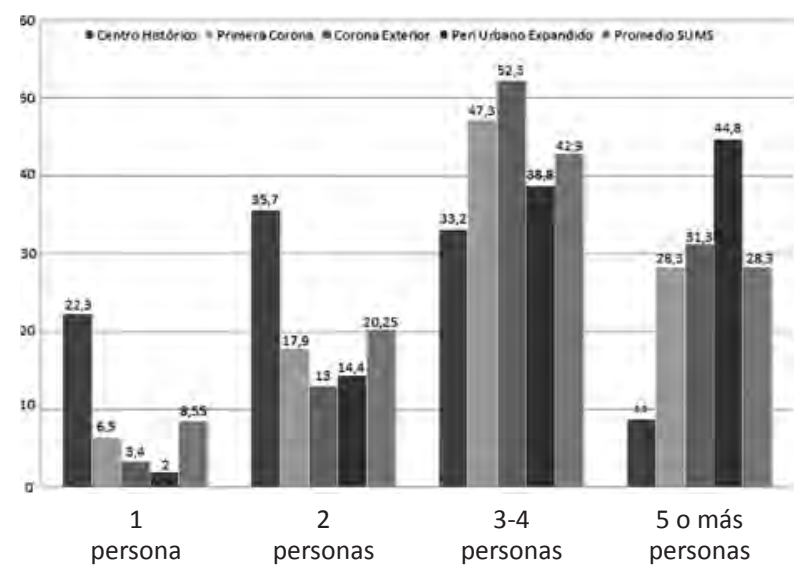

Fuente: Elaboración proyecto Fondecyt n. ${ }^{\circ} 1110387$, en base a información CASEN $2011^{34}$.

del 12\% de la proporción de viviendas del SUMS entre 1992 y 2002.

Por otro lado, se observa un crecimiento proporcional de la representatividad del parque habitacional en las comunas que componen la corona exterior, las cuales pasaron del 35\% en 1992 al $42 \%$ en 2011. También una tendencia destacable es el crecimiento constante de las comunas del

34 Si bien, la representación a nivel comunal de la encuesta CASEN 2011 es discutible, el análisis metropolitano se hace en función de conjuntos de comunas, que representan los diferentes aniIlos. En este sentido, se puede estimar un menor error, aunque no es objetivo de este trabajo calcularlo, sino más bien mostrar tendencias generales. periurbano expandido, que en el año 2011 pasaron a representar más de un 10\% de las viviendas del SUMS. Si se suma la proporción de viviendas ubicada en la corona exterior y del periurbano expandido se puede comprobar que esta creció más de 10 puntos porcentuales entre 1992 y 2012, siendo el lugar de localización de más del 52\% de las viviendas del sistema urbano.

Para matizar el análisis por condición urbana, en el gráfico $n .{ }^{03}$ se documenta la proporción que concentra cada sector del SUMS de metros cuadrados de edificación autorizada pública y privada con destino vivienda. Se observa por ejemplo, que en el primer período el centro histórico concentró casi un 6\% de la edificación, cantidad que se duplicó en el segundo período. En la primera corona, la edificación aumentó en más de 7 puntos porcentuales pasando de casi $20 \%$ a 27\% de la edificación del SUMS. Sin embargo es importante destacar las desigualdades que se producen al interior de este sector, ya que solamente cuatro comunas de un total de 22 (Providencia, Vitacura, San Miguel y Ñuñoa) concentran más del 50\% de la edificación del sector. 
La corona exterior se presenta como la única zona de la ciudad que disminuyó su participación porcentual, ya que en el primer período representaba más de 64\% de la edificación en vivienda en la ciudad y tal cifra bajó a $42 \%$ en el segundo período; sin embargo, y a pesar de esta disminución, continúa siendo la zona con mayor edificación. Finalmente, el periurbano pasa de concentrar el 8\% de la edificación a más del 14\%, multiplicando por 1,6 su participación porcentual en el SUMS.

En síntesis para el último periodo, sumando la edificación del centro histórico y la primera corona, se concluye que concentran en conjunto el $40 \%$ de la edificación en vivienda, mientras que la corona exterior y el periurbano extendido concentran el restante 58\%. Esta cifra, mucho menor a la que concentraron entre 1992 y 2002, la cual alcanzaba el 73\%, sin embargo aún continúa siendo mayoritaria.

A partir de los datos expuestos en este artículo, se puede constatar que los diferentes componentes y tendencias, en términos de crecimiento metropolitano observado durante los últimos períodos inter-censales, muestran una evolución compleja en la que se manifiestan simultáneamente fenómenos de verticalización, expansión y dispersión, tal como se ha comprobado para la gran mayoría de las grandes urbes del mundo entero, evolución que no es posible simplificar en una falsa disyuntiva entre compactación versus expansión.

\section{Nuevas geografías socio- espaciales}

En este contexto, la composición del SUMS, a nivel socio-económico y demográfico, tanto de las áreas de verticalización, como de las de expansión y dispersión urbana, reflejan también una estructura social en transformación. Esta composición explica la reproducción y ampliación de un patrón de urbanización desigual, característico de la nueva geografía metropolitana que se ha consolidado en las últimas décadas. Se entiende además, como un proceso de re/jerarquización socio espacial asociado a las nuevas formas de estratificación social. Así, tanto los cambios en el mercado del trabajo urbano y su impacto territorial, como las transformaciones asociadas a la transición demográfica y al ciclo vital de los habitantes del SUMS, son elementos importantes para dotar de sentido a esta nueva configuración socio-territorial. Desde esta perspectiva, tanto los procesos de revitalización de los centros urbanos, como el crecimiento expandido del periurbano, responden por un lado a cuestiones estructurales del modelo de acumulación, como también a cuestiones coyunturales, asociadas a nuevas formas culturales de apropiación del espacio, a reconfiguración de la familia y a la transformación de las pautas de vida colectiva. Este modelo de composición social 
está fuertemente asociado a las descripciones de Beck $^{35}$ para las sociedades europeas occidentales de la década de los '80 y '90s, es decir, al paso de una primera modernidad tradicional a una segun$\mathrm{da}$, reflexiva y que puede servir como modelo analítico para la transformación de nuestras ciudades en las últimas décadas.

Este tránsito, dado principalmente por las consecuencias sociales del colapso del Estado de bienestar, a través del fin del pleno empleo y los modelos keynesianos y fordistas en la economía y la producción respectivamente, cuestiona las pautas de vida colectiva en la ciudad y por lo tanto, modifica los patrones de localización y las formas de apropiación del espacio urbano por parte de los distintos grupos sociales. La estructura social propia de una primera etapa de modernización capitalista entra en crisis y finalmente se transforma en otra distinta $^{36}$. El tipo de estructura social resultante para esta nueva fase de modernización capitalista estaría definida, entre otros elementos, por el fin del trabajo industrial tradicional, un fuerte proceso de individualización, transformación de la familia y la inserción cada vez mayor en el proceso de globalización, entre otros. Es decir, se transforma la estructura central del aparato construido y determinado por el proceso de modernización tradicional del siglo XX, asociado a un tipo

35 Beck, 1998.

36

ARTíCULO: Tendencias recientes del crecimiento metropolitano en Santiago de Chile. ¿Hacia una nueva geografía urbana? / Carlos de Mattos, Luis Fuentes, Felipe Link determinado de familia, trabajo, espacio público y Estado. A pesar de ciertas particularidades regionales en América Latina, es claro el agotamiento de ciertas estructuras institucionales y el surgimiento de nuevas pautas de vida colectiva que responden efectivamente a una etapa diferente de la anterior y que transforman la vida urbana en su conjunto.

En este escenario, la reconfiguración de la estructura social del SUMS parece reforzar y explicar los patrones locales de metropolización. Al respecto, a continuación se analizan algunos datos de la Encuesta CASEN 2011, observados para los habitantes del SUMS, a través de la caracterización de tres aspectos fundamentales a nivel comunal, utilizados para comprender la estructura de los hogares, la familia y la condición de ocupación de la vivienda, y así levantar algunas hipótesis sobre la secuencia y tipo de ocupación del espacio urbano metropolitano contemporáneo, con algunos cambios respecto a las anteriores fases recientes.

De manera general se observa que el porcentaje de viviendas con una y hasta dos personas, es alto en Santiago. Estas cifras disminuyen notablemente en la primera corona, en el periurbano expandido y en la corona exterior, que se caracterizan por albergar familias grandes. Así, las viviendas con tres o cuatro personas suelen concentrarse 


\section{GRÁFICO 5. DISTRIBUCIÓN DE LA CANTIDAD DE DORMITORIOS DE LAS VIVIENDAS POR SECTORES DE LA CIUDAD (\%)}

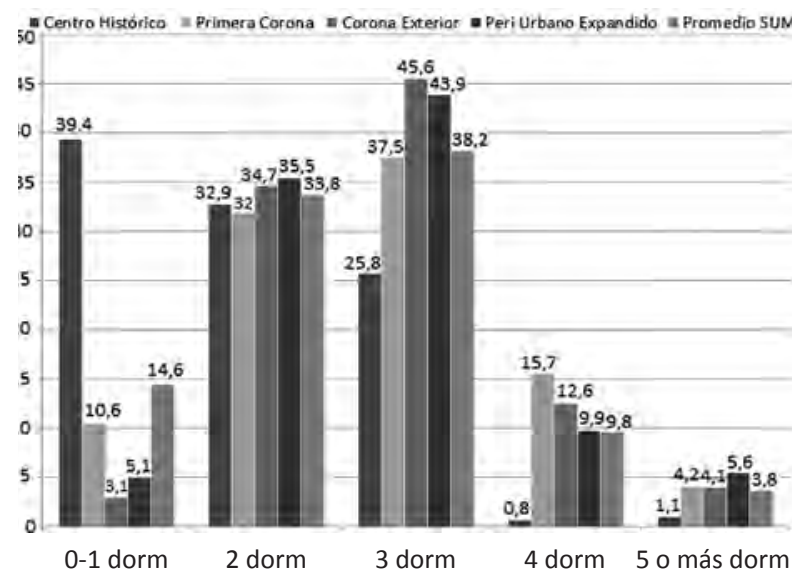

Fuente: Elaboración proyecto Fondecyt n. ${ }^{\circ} 1110387$, en base a información CASEN 2011

fuera del centro. En la primera corona y en la corona exterior éstas se distribuyen en torno al $50 \%$, mientras que en el periurbano expandido el porcentaje baja a cerca de un $40 \%$ llegando a un 30\% en Santiago. De la misma manera, los hogares con más de cinco personas, se mantienen en torno al $45 \%$ en el periurbano expandido, mientras que en Santiago no alcanzan el 10\%. Es decir, a medida que crece el número de personas por vivienda, disminuye su presencia relativa en las zonas centrales, como se observa en el gráfico n. ${ }^{\circ} 4$.

212 revista invi № 81 / Agosto 2014 / Volumen No 29: 193-219

\section{GRÁFICO 6. DISTRIBUCIÓN POR CATEGORÍA OCUPACIONAL}

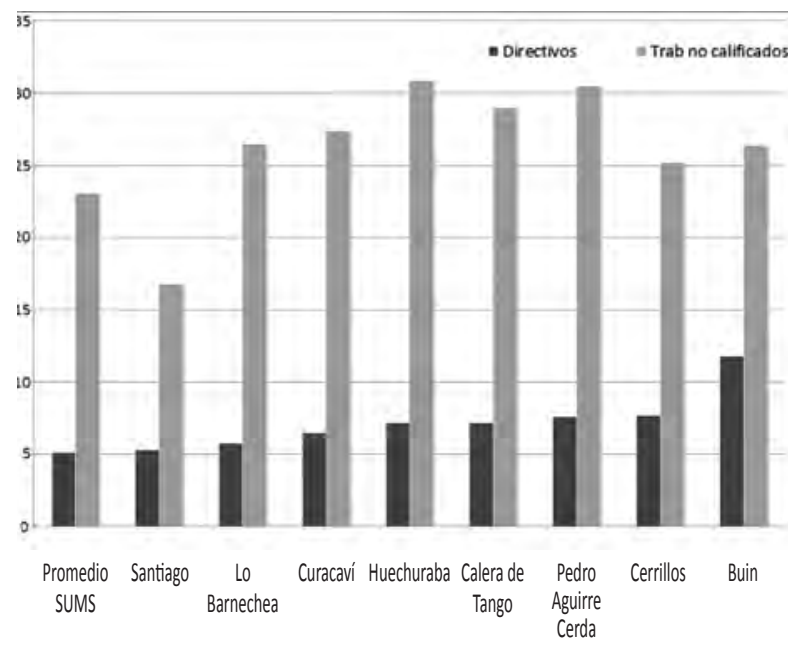

Fuente: Elaboración proyecto Fondecyt n. ${ }^{\circ} 1110387$, en base a información Encuesta CASEN 2011

En relación a la edad de los jefes de hogar, la relación es similar, en el sentido que en el centro, la jefatura de hogar es predominantemente joven, mientras que los adultos crecen relativamente en las zonas de expansión. Así por ejemplo, en el centro histórico, cerca de un 40\% de los hogares tienen jefaturas de hogar en edades dentro de 15 a 29 años, mientras que en el periurbano expandido esta cifra no supera el 10\%. Por el contrario en la corona exterior como en el periurbano expandido la mayoría de las jefaturas de hogar están en torno a los 45 y 60 años con casi un 40\% de los hogares.

ARTÍCULO: Tendencias recientes del crecimiento metropolitano en Santiago de Chile. ¿Hacia una nueva geografía urbana? / Carlos de Mattos, Luis Fuentes, Felipe Link 
De la misma manera, los datos respecto a estado civil y presencia de menores de 14 años, muestran claramente la predominancia de habitantes en tránsito en el centro de Santiago, principalmente solteros y sin hijos. Mientras, en las zonas de expansión cambia el tipo de estructura familiar. Por ejemplo, mientras en el centro histórico más de un $53 \%$ de los habitantes se declara soltero y sólo un $16,5 \%$ casado, tanto en la primera corona, corona exterior y periurbano expandido, dichos porcentajes aumentan progresivamente desde un 33\% a un $48 \%$ de casados y bajando de un $20 \%$ a un $8,2 \%$ de solteros a medida que nos alejamos del centro. En relación a la presencia de personas menores de 14 años en el hogar, por zonas del SUMS, vemos que en Santiago hay un 70,5\% de los hogares sin presencia de menores y sólo un 3,5\% con más de tres miembros del hogar menores de 14 años. Mientras en el periurbano expandido el porcentaje de hogares sin presencia de menores baja a $28 \%$ y sube a $12,5 \%$ con más de tres personas en este rango etario.

Las consecuencias urbanas de estos procesos tienen que ver con el tipo de ocupación del espacio y demanda de servicios que uno u otro grupo genera. El crecimiento en expansión del SUMS se explica por cuestiones estructurales, pero también por la demanda de cierto tipo de equipamiento para servir a las familias predominantes en estas nuevas localizaciones. Por otra parte, se observa que el impacto territorial en cuanto, - y por ejemplo -, al tipo de desarrollo inmobiliario que se consolida en cada sector, es predominantemente de viviendas de uno o dos dormitorios en el centro, incluyendo incluso un porcentaje menor de departamentos "studio" sin dormitorios, y donde la gran mayoría en el área central tienen al arriendo como forma de tenencia de vivienda (63\%). Por el contrario, en la primera corona y las zonas de expansión, la vivienda es principalmente propia, pagada, pagándose $u$ otra condición diferente al arriendo (primera corona $62,6 \%$; corona exterior $56 \%$; periurbano expandido $56 \%$ ).

El gráfico n. ${ }^{\circ} 5$ muestra la distribución del número de dormitorios en cada vivienda por zona.

Con todos estos datos, obtenidos de la Encuesta de Caracterización Socio Económica Nacional (CASEN) de 2011, es posible observar una estructura socio-demográfica diferente para el centro de Santiago en relación a las coronas pericentrales y exteriores. La evolución poblacional y de vivienda, descrita más arriba, nos permite inferir una transformación similar en cuanto a la estructura social. Es decir, que los habitantes del centro de Santiago corresponden principalmente a residentes de paso, que probablemente emigrarán a comunas periféricas en la medida en que cambie su situación personal y familiar.

En este sentido, son interesantes los datos obtenidos sobre migración intra y extra metropolitana 
para el SUMS, así como los datos sobre categorías socio ocupacionales en las diferentes comunas del sistema urbano metropolitano. En base a los datos de la encuesta CASEN de 2011, es posible hacer un análisis de la procedencia y desplazamiento de los habitantes de las comunas del SUMS, a partir de la pregunta sobre procedencia de la población hace 5 años (2006). Podemos comprobar que en el centro es donde hay una mayor cantidad de migrantes, alcanzando casi un 30\% e incluyendo migrantes nacionales intrametropolitanos (12,9\%), extrametropolitanos $(11,7 \%)$ y un $5,1 \%$ de migrantes internacionales.

Esta distribución disminuye considerablemente en la primera corona, donde los migrantes intrametropolitanos alcanzan un 7,3\%, mientras que los migrantes extrametropolitanos llegan solo a un $2,2 \%$. La corona exterior y el periurbano expandido se mantienen similares, alcanzando un máximo de $6 \%$ de migrantes intrametropolitanos. Es decir, que el centro aún mantiene una condición de espacio receptor de la migración nacional. Si bien, es cierto que Santiago ha visto decrecer la migración desde las regiones hacia la capital, ésta aún persiste y parece afectar principalmente al centro del SUMS. Mientras, los desplazamientos intrametropolitanos, corresponden a una movilidad interna, que refuerza los patrones expansivos del sistema.

En este sentido, el gráfico n. ${ }^{\circ} 6$ muestra una variable importante para el análisis de las características de los procesos urbanos en curso, como es la categoría socio ocupacional de la población. Dicha distribución, muestra cómo la migración intrametropolitana se compone en gran medida por los extremos de la jerarquía socio ocupacional, contribuyendo a la hipótesis de una expansión fragmentada del SUMS. En algunas comunas representativas de esta tendencia, como Calera de Tango, Buin, San José de Maipo o Curacaví, podemos comprobar que la proporción de las categorías socio ocupacionales superiores e inferiores, es decir, directivos y trabajadores no calificados, supera a veces ampliamente a la media del SUMS, acercándose a la distribución de comunas como Peñalolén, por ejemplo.

A la luz de estos resultados, la estructura y composición social del territorio metropolitano de Santiago aparecen como elementos importantes al momento de cualificar ciertas tendencias contemporáneas de crecimiento urbano, reforzando la idea de un patrón socio-territorial expansivo y desigual.

\section{Conclusiones}

El análisis de la información considerada en este trabajo, sobre los cambios en el parque habitacional en las diversas comunas de la RMS en el período 1992-2002-2011, así como de algunas transformaciones socio demográficas, permite esbozar 
algunas conclusiones respecto a las principales tendencias que han afectado al crecimiento del SUMS. Estas tendencias indican que, al mismo tiempo que se ha producido un retorno al centro, se ha mantenido un crecimiento territorial disperso en constante expansión. En este sentido, las cifras analizadas en este artículo indican lo siguiente:

- Las comunas del SUMS en las que se observa un mayor crecimiento del stock de viviendas en el período indicado, con la excepción de las comunas de Santiago, Nuñoa y Providencia se encuentran localizadas en la corona externa del AMS; entre las 10 comunas que registran un mayor crecimiento del número de viviendas en este período, 7 de ellas se ubican en la corona externa y 3 en el núcleo urbano tradicional.

- Las comunas en las que se produjo un mayor crecimiento de viviendas en el último período considerado son diversas en términos geográficos ya que están ubicadas en la corona exterior del AMS, en el periurbano expandido, pero también en el centro y y primera corona, lo cual muestra una complejización de las tendencias al interior del sistema urbano.

- A pesar de estas tendencias diversas, al considerar la proporción de viviendas de las distintas zonas y el aporte de las modalidades de crecimiento urbano a la evolución del SUMS, la propensión al desplazamiento hacia fuera sigue siendo la principal fuerza de crecimiento urbano, no obstante la disminución de su intensidad entre 2002 y 2011, respecto al período anterior.

- En relación a la estructura y composición socio demográfica del SUMS, es posible sostener, a partir de la información preliminar a nivel de comuna, que existen tres características principales: a) los procesos de verticalización del centro corresponden a un tipo de habitante pasajero, joven, soltero y sin hijos, que habita viviendas pequeñas, arrendadas y que emigrará hacia fuera en la medida en que se modifique su situación familiar; b) el centro del SUMS concentra una proporción importante de los migrantes extra metropolitanos, actuando como receptor temporal del SUMS; y c) las coronas periféricas reciben la migración intrametropolitana de familias en formación, reforzando los patrones de urbanización desigual, ya que concentran los extremos de la jerarquía social.

Habida cuenta de estas tendencias, se puede concluir, que la tendencia dominante de crecimiento del área urbana del SUMS continúa siendo hacia la expansión y dispersión territorial metropolitana, en una dinámica que desborda las comunas y territorios tradicionalmente reconocidos como parte del denominado Gran Santiago o AMS. Esto indica que las formas de vida y los comportamientos propiamente urbanos continúan imponiéndose en un 
territorio cada vez más extenso, en concordancia con la persistencia del proceso de urbanización de la economía.

La verticalización habitacional de algunas comunas centrales del AMS, como es el caso del significativo crecimiento del stock de viviendas de la comuna de Santiago, así como en menor medida en las comunas de Ñuñoa, Providencia y San Miguel, no es contradictoria con un fuerte crecimiento de diversas comunas ubicadas tanto en la corona externa como en el periurbano conurbado y no conurbado, con lo cual la metáfora "mancha de aceite" ha ido perdiendo pertinencia.

A la luz de la información sobre los cambios en el número de viviendas en el período analizado, se puede comprobar que verticalización, expansión y dispersión, aparecen como tendencias complementarias en el contexto de un proceso de urbanización difusa y reticular, en el cual se expresan al mismo tiempo las consecuencias de la diversificación de la composición de los núcleos familiares metropolitanos. Conviven desde personas solas o parejas que prefieren la localización central, aun cuando con alta rotación, hasta grupos familiares nucleares que optan por la casa individual con jardín o por los barrios jardín suburbanos, lo cual aparece como una tendencia que afecta a todos los estratos socio-económicos y en todo el perímetro metropolitano.
En esta dirección, a nuestro juicio, resulta peligrosa la interpretación de que el crecimiento urbano actual en torno al AMS se manifestaría como un inexorable retorno hacia una ciudad más compacta, dado que ella conlleva dos supuestos implícitos, que de ser aceptados por la opinión pública y por los gobiernos urbanos, en especial en una situación en la que ha cobrado relevancia la discusión de una nueva política urbana, tenderían a reforzar la postura a favor de la continuidad de una gobernanza neoliberal. Tales mensajes serían los siguientes:

- En primer lugar, y dado que según esa interpretación, la tendencia a la expansión y dispersión territorial urbana habría sido neutralizada y/o revertida por la propia dinámica de crecimiento urbano, sería conveniente persistir en la lectura de que una mayor liberalización es el camino más apropiado para lograr una mejor configuración urbana.

- En segundo lugar, y como corolario de lo anterior, también se podría inferir que los poderes y/o administraciones públicas no deberían preocuparse por el deterioro de las áreas centrales, ya que el mercado estaría actuando para corregir los problemas que las ha estado afectando.

Frente a ello, y a la luz de la evidencia que se expone en este trabajo, se reafirma la conclusión que para interpretar y explicar la complejidad de

ARTÍCULO: Tendencias recientes del crecimiento metropolitano en Santiago de Chile. ¿Hacia una nueva geografía urbana? / Carlos de Mattos, Luis Fuentes, Felipe Link 
los procesos actuales de transformación urbana, resulta ineludible considerar el encuadramiento estructural vigente en un mundo globalizado, donde el vertiginoso aumento de la conectividad y la movilidad, y la consecuente ampliación territorial del campo de externalidades, tienen una incidencia crucial en el comportamiento locacional de las familias y de las empresas. Aun cuando los efectos de estos factores se manifiestan con diferencias específicas en cada una de las aglomeraciones urbanas afectadas, no es posible soslayar la existencia de un conjunto de tendencias genéricas que marcan su presencia por igual en todas ellas en diversos lugares del mundo, como ha sido documentado por los últimos estudios realizados por Habitat/ONU.

En este escenario, el SUMS no ha sido ajeno a estas tendencias genéricas, las cuales, por otra parte, van en la misma dirección de las que se han observado tanto en la mayor parte de las grandes megalópolis de la región, como es el caso de Ciudad de México, Sao Paulo, Buenos Aires, Rio de Janeiro y Bogotá, entre otras, así como también en el de áreas urbanas de menor dimensión como, Quito, Montevideo, Ciudad de Panamá, San José de Costa Rica, etc., en las que tanto "concentración", "expansión" y "dispersión" son fenómenos que se manifiestan, bajo diversas modalidades e intensidad, en el actual proceso de crecimiento y transformación urbana. Sostener que la transformaciones para el caso de la región urbana que se ha estado configurando a partir del AMS estarían siguiendo una dirección opuesta a las que se observan en la metamorfosis urbana en todo el mundo, carece de fundamento tanto teórico como empírico.

\section{Bibliografía}

ALONSO, Guillermo. El Censo 2010: datos preliminares, algunas observaciones, también preliminares. [En línea]. Población. 4(7): 67-74, julio 2011. ISSN: 1852-074X. Disponible en: http://www. mininterior.gov.ar/poblacion/pdf/poblacion_07. pdf.

BECK, Ulrich. La sociedad del riesgo: hacia una nueva modernidad. Barcelona, España, Paidós. 1998 304 p. ISBN 978-84-493-0406-4.

BRENNER, Neil. Tesis sobre la urbanización planetaria. Nueva Sociedad. (243): 38-66, enero, 2013. ISSN 0251-3552.

CASTELLS, Manuel. Globalisation, networking, urbanisation: reflections on the spatial dynamics of the information age. [En línea]. Urban Studies. 47(13): 2737-2745, November 2010. Disponible en: http:// dx.doi.org/10.1177/0042098010377365.

CIDU. Síntesis del estudio región central de Chile: perspectivas de desarrollo. Santiago, Chile, U.C.-CIDU.1971.

DAMON, Julien. Comment definir stastiquiment l'urbain? [Enlínea].Urbanisme, (384): 7, mayo-junio 2012. Disponible en: http://www.urbanisme.fr/issue/magazine.php?code=384\&section=AGORA .

revista invi № 81 / Agosto 2014 / Volumen № 29: 193-219 217 
DEMATTEIS, Giuseppe. Suburbanización y periurbanización. Ciudades anglosajonas y ciudades latinas. En: MONCLUS, Francisco Javier, ed. La ciudad dispersa. Suburbanización y nuevas periferias. Barcelona, Centre de Cultura Contemporánia de Barcelona. 1998. p. 17-34. ISBN 84-88811-35-7.

DUCCI, María Elena. Santiago, ¿una mancha de aceite sin fin? ¿Qué pasa con la población cuando crece indiscriminadamente? [En línea]. EURE. 24(72): 85-94, septiembre 1998. ISSN 0717-6236. [Fecha de consulta: 15 julio 2013]. Disponible en: http:// dx.doi.org/10.4067/S0250-71611998007200005.

ESCOLANO, Severino y ORTIZ, Jorge. Patrones espaciales de movilidad de la población: algunos efectos en la sociogeografía del Gran Santiago. En: MATTOS, Carlos de, ed. e HIDALGO, Rodrigo ed. Movilidad espacial y reconfiguración metropolitana. Santiago, Chile, Instituto de Estudios Urbanos y Territoriales, Instituto de Geografía, Pontificia Universidad Católica de Chile. 2007. p. 53-66. Colección EURE-LIBROS; SERIE GEOlibros No 8. ISBN 9789561409439

FUENTES, Luis y SIERRALTA, Carlos. Santiago de Chile, iejemplo de una reestructuración capitalista global? [En línea]. EURE. (30)91: 7-28, diciembre 2004. ISSN 0250-7161. Disponible en: http:// dx.doi.org/10.4067/S0250-71612004009100002.

GREENE, Margarita y SOLER, Fernando. Santiago: de un proceso acelerado de crecimiento a uno de transformaciones. En: MATTOS, Carlos, ed., et al. Santiago en la globalización: ¿Una nueva ciudad?

218 revista invi № 81 / Agosto 2014 / Volumen No 29: 193-219
Santiago de Chile, Ediciones SUR. 2004. p. 17-46. ISBN 9562080722.

HARVEY, David. From managerialism to entrepreneurialism: the transformation in urban governance in late capitalism. Geografiska Annaler. Series B, Human Geography. 71(1): 3-17, 1989. ISSN 1468-0467.

— The condition of postmodernity. An enquiry into the origins of culture change. Oxford, U.K., Blackwell Publishers. 1990. 378 p. ISBN 0-631-1622-5.

HIDALGO, Rodrigo; BORSDORF, Axel y SÁNCHEZ, Rafael. La expansión residencial amurallada en la reconfiguración metropolitana de Santiago de Chile. En: MATTOS, Carlos de, ed. e HIDALGO, Rodrigo ed. Movilidad espacial y reconfiguración metropolitana. Santiago, Chile, Instituto de Estudios Urbanos y Territoriales, Instituto de Geografía, Pontificia Universidad Católica de Chile. 2007. Colección EURE-LIBROS; SERIE GEOlibros No 8. ISBN 9789561409439.

INE. Censo de población y vivienda 1992. Santiago, Chile.

_ Censo de población y vivienda 2002. Santiago, Chile.

_ Censo de población y vivienda 2012. Santiago, Chile.

_ Precenso de viviendas particulares por región y comuna 2011. Santiago, Chile.

LEFEBVRE, Henri. La revolution urbaine. Paris, Gallimard. 1970. 248 p.

ARTíCULO: Tendencias recientes del crecimiento metropolitano en Santiago de Chile. ¿Hacia una nueva geografía urbana? / Carlos de Mattos, Luis Fuentes, Felipe Link 
LÓPEZ-MORALES, Ernesto; GASIC KLETT, Ivo Ricardo y MEZA CORVALÁN, Daniel Alberto. Urbanismo pro-empresarial en Chile: políticas y planificación de la producción residencial en altura en el pericentro del Gran Santiago. [En línea]. Revista INVI. (27)76: 75-114, noviembre 2012. ISSN 07188358. Disponible en: http://dx.doi.org/10.4067/ S0718-83582012000300003.

MATTOS, Carlos de y FUENTES, Luis. Crecimiento de la población de Santiago entre 2002 y 2012: icompactación o expansión? Una falsa disyuntiva. Revista Planeo. (8), agosto, 2013. ISSN 0719-2932.

MATTOS, Carlos de. Santiago de Chile: metamorfosis bajo un nuevo impulso de modernización capitalista. En: MATTOS, Carlos, ed., et al. Santiago en la globalización: ¿Una nueva ciudad? Santiago de Chile, Ediciones SUR. 2004. p. 17-46. ISBN 9562080722.

OBSERVATÓRIO das Metrópoles. As metrópoles no Censo 2010: novas tendencias?. [En línea]. Observatório das metrópoles. 2011. Disponible en: http://observatoriodasmetropoles.net/index. php?option=com_content\&view=article $\&$ id $=154$ 1 \& catid $=45 \&$ Itemid $=88 \% \mathrm{E} 2 \% 8 \mathrm{C} \% \mathrm{~A} 9=\mathrm{pt}$.

OECD. Redefining "urban". A new way to measure metropolitan areas. Paris, OECD. 2012. 148 p. ISBN: 978-92-6-417405-4.

ONU-HABITAT. Estado de las ciudades de América Latina y el Caribe. Rumbo a la nueva transición urbana. Brasil, UN-HABITAT. 2012. 172 p. ISBN 978-92-1-132469-3.

RED de Observatorio de la Comunidad Europea. Informe marco México D. F. [En línea]. Ayuntamiento de Madrid. 2011. Disponible en: http://www.madrid. es/UnidadesDescentralizadas/UDCObservEconomico/RedObserDesPart/Estudios\%20y\%20Publicaciones/Ficheros/MEXICO\%20DF.pdf.

RIBEIRO, Luiz Cesar 0.; RODRIGUES, Juciano M. y SILVA, Erica T. Metropoles brasileiras: diversificacão, concentração y dispersão. Revista Paranaense de Desenvolvimento. (120): 177-207, enero 2011. ISSN 0556-6916. Disponible en: http://www.ipardes.pr.gov.br/ojs/index.php/revistaparanaense/ article/view/232/674

RODRÍGUEZ VIGNOLI, Jorge. ¿Policentrismo o ampliación de la centralidad histórica en el Área Metropolitana del Gran Santiago? Evidencia novedosa proveniente de la encuesta Casen 2009. [En línea]. EURE. 38(114): 71-97, mayo 2012. ISSN 0717-6236. [Fecha de consulta: 07 abril 2013]. Disponible en: http://dx.doi.org/10.4067/ S0250-71612012000200003.

SOJA, Edward. Postmodern geographies. The reassertion of space in critical social theory. New York, Verso. 1989. 266 p. ISBN 0-086091-936-6. 